Hydrol. Earth Syst. Sci., 12, 1295-1307, 2008

www.hydrol-earth-syst-sci.net/12/1295/2008/

(C) Author(s) 2008. This work is distributed under

the Creative Commons Attribution 3.0 License.

\title{
Runoff thresholds in derived flood frequency distributions
}

\author{
A. Gioia ${ }^{1}$, V. Iacobellis ${ }^{1}$, S. Manfreda ${ }^{2}$, and M. Fiorentino ${ }^{2}$ \\ ${ }^{1}$ Dipartimento di Ingegneria delle Acque e di Chimica, Politecnico di Bari, Bari, Italy \\ ${ }^{2}$ Dipartimento di Ingegneria e Fisica dell'Ambiente, Università degli Studi della Basilicata, Potenza, Italy
}

Received: 17 January 2008 - Published in Hydrol. Earth Syst. Sci. Discuss.: 1 April 2008

Revised: 18 September 2008 - Accepted: 26 September 2008 - Published: 1 December 2008

\begin{abstract}
In general, different mechanisms may be identified as responsible of runoff generation during ordinary events or extraordinary events at the basin scale. In a simplified scheme these mechanisms may be represented by different runoff thresholds. In this context, the derived flood frequency model, based on the effect of partial contributing areas on peak flow, proposed by Iacobellis and Fiorentino (2000), was generalized by providing a new formulation of the derived distribution where two runoff components are explicitly considered. The model was tested on a group of basins in Southern Italy characterized by annual maximum flood distributions highly skewed. The application of the proposed model provided good results in terms of descriptive ability. Model parameters were also found to be well correlated with geomorphological basin descriptors. Two different threshold mechanisms, associated respectively to ordinary and extraordinary events, were identified. In fact, we found that ordinary floods are mostly due to rainfall events exceeding a threshold infiltration rate in a small source area, while the so-called outlier events, responsible of the high skewness of flood distributions, are triggered when severe rainfalls exceed a threshold storage in a large portion of the basin.
\end{abstract}

\section{Introduction}

Today's research on flood prediction is strongly focused on the reduction of uncertainty with particular attention to ungauged basins (e.g. Sivapalan et al., 2003). Two main approaches can be distinguished in this field: the first one is based on regional analysis as a tool for identifying hydrologic similarity, and mainly relies on statistical analysis of

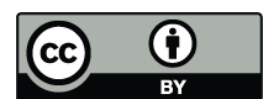

Correspondence to: A. Gioia

(a.gioia@poliba.it) data; the second one more closely investigates the physical processes, acting at hillslope and basin scales, by field experiments and advanced simulation modelling. In this general framework, methods based on the theoretical derivation of flood frequency distribution may represent a way to increase process understanding and bridge the two approaches enhancing their reciprocal support. A technical use of derived distributions of flood frequency is still far from operational. But, the immediate outcome of their development lies in a deeper knowledge of hydrological controls in extreme events. Through this progress, designated factors depending on climate, soil and vegetation should be eligible as signatures for the identification of hydrological heterogeneity and similarity.

In principle, the flood distribution can be derived using rainfall distribution and a rainfall-runoff model which includes water losses and flow routing. Eagleson (1972) tackled the problem by first modelling it analytically. After this pioneering work, further investigations on this matter have been performed (e.g. Haan and Edwards, 1988; Raines and Valdes, 1993; Kurothe et al., 1997; Gottschalk and Weingartner, 1998; Goel et al., 2000; De Michele and Salvadori, 2002; Franchini et al., 2005). Among others, Sivapalan et al. (1990) accounted for the effect of different mechanisms of runoff generation (infiltration excess and saturation excess) while Sivapalan et al. (2005) strongly focused on the role of seasonality and used mixed distributions. Iacobellis and Fiorentino (2000) introduced the partial contributing area as a random variable and considered only one runoff threshold mainly associated either to infiltration excess in arid basins or to saturation excess in humid basins. Other authors numerically evaluated the flood frequency distribution through Monte Carlo simulations (e.g. Consuegra et al., 1993; Muzik, 1993; Loukas, 2002) or by continuous simulation (e.g. Beven, 1987; Bras et al., 1985; Blazkova and Beven, 2002; Fiorentino et al., 2007). These

Published by Copernicus Publications on behalf of the European Geosciences Union. 
combine a stochastic rainfall forcing with a reliable representation of physical dynamics affecting basin response. In particular, Fiorentino et al. (2007) used a distributed hydrological model (Manfreda et al., 2005) in cascade with a rainfall generator with multifractal properties (Veneziano and Iacobellis, 2002). They investigated the role of climate, soil and vegetation in runoff generation during extreme events and concluded that runoff source areas are mainly affected by pedologic features in arid basins, while a geomorphologic control prevails in humid basins.

The effects of runoff thresholds have received particular attention in flood frequency analysis in last few years (e.g. McGrath et al., 2007). Kusumastuti et al. (2007) focused on catchment storage and derived the flood frequency distributions by Monte Carlo simulations, using a non-linear conceptual rainfall-runoff model. Struthers and Sivapalan (2007) analysed the influence on flood frequency of spatial heterogeneity in non-linear thresholds, seasonal variability in storms, and space-time variability in the storage-discharge relationship associated with the rainfall-runoff process. They observed that temporal variability in seasonal storms increases the frequency of threshold exceedence and the magnitude of the flood response associated with a given runoff process. Interestingly, spatial variability in landscape and climatic properties provides a spatial variability in the local frequency of threshold exceedence, while the decreasing of soil depth towards the stream masks the impacts of threshold upon the resulting flood frequency. Working on a runoff threshold and exploiting the theoretical model proposed by Iacobellis and Fiorentino (2000), Iacobellis et al. (2002) explored the spatial variability of the coefficient of variation of annual maximum floods.

In the present work, we generalize the theoretical probability distribution proposed by Iacobellis and Fiorentino (2000) introducing a two component derived distribution where the role of runoff thresholds is emphasized. Thus, we improve the descriptive properties of the theoretically derived distribution with particular attention to its ability of coping with the so-called "condition of separation" of Matalas, (i.e. high dispersion of coefficients of skewness in annual maximum floods, Matalas, 1975; Cunnane, 1986). Then, a phenomenological interpretation of highly skewed distributions is provided.

We also investigate the role of climate, soil and geomorphology on runoff thresholds with particular focus on the way they affect runoff source areas.

\section{Theoretically derived flood frequency distribution (IF model)}

Iacobellis and Fiorentino (2000) proposed a theoretically derived flood frequency distribution hereinafter referred to as "IF" model.
The IF model is based on the concept of partial contributing (or source) area and relies on the following assumptions. The peak of direct streamflow $Q$ is the product of two random variables strongly correlated, the source area contributing to runoff peak $a$ and the runoff peak per unit of $a, u_{a}$. Both random variables are controlled by: (i) rainfall intensity, duration and areal extension; (ii) runoff concentration; (iii) hydrological losses. The probability distribution of $u_{a}$, can be derived from the probability distribution of rainfall intensity conditional on a duration equal to $\tau_{a}$, lag-time of $a$. The lag time is intended as the lag of direct runoff centroid to effective rainfall centroid. The runoff peak per unit area, $u_{a}$, is linearly dependent on the areal net rainfall intensity in a time interval equal to $\tau_{a}$.

Fiorentino et al. (1987), by means of numerical simulations, showed that, within a large range of observed intensityduration-frequency (IDF) curves and of basin response functions, the basin lag-time is close to the critical rainfall duration (the one maximizing the flood peak). Moreover, they found that a constant routing factor $\xi$, close to 0.7 , fairly well represents the ratio of peak runoff to net rainfall intensity in $\tau_{a}$.

Thus, the runoff per unit area is

$u_{a}=\xi\left(i_{a, \tau}-f_{a}\right)$,

where $i_{a, \tau}$ is the average areal rainfall intensity in $\tau_{a}$ covering the contributing area $a, f_{a}$ is the corresponding spacetime averaged hydrologic loss. The exceedance probability function of the peak of direct streamflow $Q, G_{Q}^{\prime}(q)$, is found as the integral of the joint probability density function (pdf) of $a$ and $u_{a}$

$G_{Q}^{\prime}(q)=\int_{0}^{A} \int_{\frac{q}{u_{a}}}^{\infty} g(u \mid a) g(a) d u d a$,

where runoff peak $u_{a}$ is expressed as $u \mid a$ (i.e. $u$ conditional on $a$ ).

The pdf of $u_{a}$ is found from the pdf of areal rainfall intensity $i_{a, t}$ which is assumed Weibull distributed with two parameters $\theta$ and $k$ :

$g\left(i_{a, \tau}\right)=\frac{k}{\theta_{a, \tau}} i_{a, \tau}^{k-1} \exp \left(-\frac{i_{a, \tau}^{k}}{\theta_{a, \tau}}\right)$,

with

$\theta_{a, \tau}=E\left[i_{a, \tau}^{k}\right]=\left(E\left[i_{a, \tau}\right] / \Gamma(1+1 / k)\right)^{k}$.

The lag-time $\tau_{a}$ scales with $a$ according to a power law with exponent 0.5 .

The IF model assumes that a power law relationship also exists between $E\left[i_{a, \tau}\right]$ and $a$

$E\left[i_{a, \tau}\right]=i_{1} a^{-\varepsilon}=E\left[i_{A, \tau}\right](a / A)^{-\varepsilon}$ 
and between $f_{a}$ and $a$

$f_{a}=f_{1} a^{-\varepsilon^{\prime}}=f_{A}(a / A)^{-\varepsilon^{\prime}}$,

where $i_{1}$ and $f_{1}$ are respectively the average rainfall intensity and the average hydrologic loss on the unit of contributing area, while $E\left[i_{A, \tau}\right]$ and $f_{A}$ are referred to the entire basin area $A$.

Under the hypothesis that the rate of occurrence of rainfall exceedances over the threshold $f_{A}$ is Poisson distributed and being rainfall intensity Weibull distributed with parameter $k$, the following relationship holds:

$\Lambda_{q}=\Lambda_{p} \exp \left(-\frac{f_{A}^{k}}{E\left[i_{A, \tau}^{k}\right]}\right)$

where $\Lambda_{q}$ is the mean annual number of floods, and $\Lambda_{p}$ is the mean annual number of rainfall events.

Fiorentino and Iacobellis (2001) investigated the variability of $f_{A}$ in real basins. They used Eq. (7) with available estimates of other values $\left(\Lambda_{q}, \Lambda_{p}, k, E\left[i_{A, \tau}\right]\right)$ in order to estimate the $f_{\mathrm{A}}$ values. They found that Eq. (6) holds in arid and semi-arid basins of Puglia and Basilicata with parameters values $f_{1}=37\left[\mathrm{~mm} \mathrm{~h}^{-1} \mathrm{~km}^{-2} \varepsilon^{\prime}\right]$ and $\varepsilon^{\prime}=0.5$. In humid basins they found low values and low variability of $f_{A}$, providing the following estimates: $f_{1}=0.7\left[\mathrm{~mm} \mathrm{~h}^{-1} \mathrm{~km}^{-2} \varepsilon^{\prime}\right]$ and $\varepsilon^{\prime}=0$.

The scaling behaviour of $f_{a}$ represents a significant signature of basin hydrological response. Fiorentino and Iacobellis (2001; Sect. 5.1) also showed that a value of $\varepsilon^{\prime}=0.5$ means that runoff occurs when a storage capacity has been exceeded in the source area. This was found in arid basins where a long dry period is likely expected before rainfall events. Thus, runoff source area is controlled by pedology and vegetation density consistently with an infiltration excess mechanism where infiltration is mainly affected by initial adsorption due to vegetation interception and soil storage capacity. The spatial variability of soil storage capacity, with particular regard to scarcely vegetated and less permeable areas, is also expected to play an important role. On the other hand, a value of $\varepsilon^{\prime}=0$ indicates the existence of a constant runoff threshold conventionally related to the average infiltration rate of the soil-bedrock system in saturated conditions (Fiorentino and Iacobellis, 2001; Sect. 5.3). This behaviour was observed in humid and semi-humid basins. In fact, in basins subject to frequent precipitations, a buffer area covered by dense vegetation along the stream network is likely characterized by wet soil moisture condition before any rainfall event. This area can yield surface runoff even for low rainfall intensity. In this process source areas may expand and contract depending on rainfall intensity as well as on surface and subsurface conditions, but source areas expected value is always a small fraction of the entire basin area mainly controlled by topography.
These considerations also have implications for the distribution of variable contributing area $a$ whose pdf $g(a)$ is sum of a continuous gamma function $\Gamma(\alpha, \beta)$ and the probability $P_{A}=\operatorname{prob}[a=A]$ by the Dirac function $\delta($.)

$g(a)=\frac{1}{\alpha \Gamma(\beta)}\left(\frac{a}{\alpha}\right)^{\beta-1} \exp \left(-\frac{a}{\alpha}\right)+\delta(a-A) P_{A}$

Parameters $\alpha$ and $\beta$ respectively control position and scale of the Gamma distribution and the following relationship holds

$\alpha=r A / \beta$

where $r$ is

$r=E[a] / A$.

According to a geomorphological interpretation by Iacobellis and Fiorentino (2000) the expected value of $\beta$ is equal to 4.

Thus, under the hypothesis that the annual maximum floods arise from a compound Poisson process, Iacobellis and Fiorentino (2000) derived the cumulative distribution function (cdf) of the annual maximum flood peak by means of the relationship

$F_{q_{p}}\left(q_{p}\right)=\exp \left\{-\Lambda_{q}\left\lfloor G_{Q}^{\prime}\left(q_{p}\right)\right\rfloor\right\}$,

where

$Q_{p}=Q+q_{o}$,

with $q_{o}$ is the base flow.

Further analyses were conducted on arid basins (Fiorentino and Iacobellis, 2001) where the parameter $r$ showed a significant correlation with a permeability index defined as $\psi=\psi_{h}+0.9 \psi_{m}$ where $\psi_{h}$ and $\psi_{m}$ are fractions of the total basin area with bedrock characterized by high and medium permeability, respectively.

Fiorentino et al. (2003) also found that the $r$ estimates, in arid basins, were well correlated to the runoff coefficient $C$ proposed by De Smedt et al. (2000), which depends on soil type, land-use and local slope. Moreover they provided a quantitative assessment of the morphological control on source areas in humid basins. In fact, a strong correlation between the expected value of contributing area and the variation coefficient of the topographic index proposed by Beven and Kirkby (1979) was found.

\section{Two Component IF model (TCIF)}

Earlier applications of the IF model allowed to identify two different response types in basins of Southern Italy. In fact, depending on several factors including climate, geomorphology, soil-bedrock features, one of these mechanisms could prevail over the others. Nevertheless it is well known that, in general, different mechanisms may arise, in any basin, with different frequency and weight (e.g. Sivapalan et al., 1990). 
Thus, in particular basins, different mechanisms may coexist, being in turn responsible of peak runoff depending on the characteristics of the rainfall event and on the soilbedrock antecedent conditions. Let us introduce two different threshold-driven processes defined as:

- L-type (frequent) response, occurring when a lower threshold is exceeded, and responsible of ordinary floods likely produced by a relatively small portion of the basin;

- H-type (rare) response, occurring when a higher threshold is exceeded, and providing extraordinary floods mostly characterized by larger contributing areas.

Thus, a process-based support is provided for two component probability distributions. Among these there is the TCEV (Two Component Extreme Events, Rossi et al., 1984), which is largely used in regional flood frequency analysis.

Based on this rationale, a new two component probability distribution is herein proposed. It has been given the name "Two Component IF distribution" (TCIF), being a generalization of the IF distribution. In particular, Eqs. (3), (4), (5), (8), (9) and (12) remain unchanged while the following relationships are introduced.

The L-type (frequent) peak unit runoff arises whereas rainfall intensity exceeds the lower threshold $f_{a, L}$ to form a contributing area $a_{L}$ :

$u_{a, L}=\xi\left(i-f_{a, L}\right)$

Analogously, the H-type (rare) peak unit runoff arises whereas rainfall intensity exceeds the higher threshold $f_{a, H}$ to form a contributing area $a_{H}$ :

$u_{a, H}=\xi\left(i-f_{a, H}\right)$

Equations (13) and (14) include the routing factor $\xi$, which is independent from the runoff generation mechanism, while $f_{a, L}$ and $f_{a, H}$ scale with contributing area according to the following power law relationships:

$$
\begin{aligned}
& f_{a, L}=f_{A, L}\left(a_{L} / A\right)^{-\varepsilon_{L}} \\
& f_{a, H}=f_{A, H}\left(a_{H} / A\right)^{-\varepsilon_{H}}
\end{aligned}
$$

The flood-peak contributing areas $a_{L}$ and $a_{H}$ are assumed, in analogy with the IF model, as Gamma distributed (Eq. 10), with $\beta=4$, and different mean values. Therefore, two dimensionless parameters are introduced:

$r_{L}=E\left[a_{L}\right] / A$

$r_{H}=E\left[a_{H}\right] / A$

with $r_{H} \geq r_{L}$.
The corresponding peak flow distributions are:

$G_{Q, L}^{\prime}(q)=\int_{0}^{A} \int_{\frac{q}{a}}^{\infty} g\left(u \mid a_{L}\right) g\left(a_{L}\right) d u d a_{L}$

for L-type (frequent) events and

$G_{Q, H}^{\prime}(q)=\int_{0}^{A} \int_{\frac{q}{a}}^{\infty} g\left(u \mid a_{H}\right) g\left(a_{H}\right) d u d a_{H}$

for H-type (rare) events.

Assuming that L-type and H-type events are independent and that both rates of occurrence are Poisson distributed, the overall process of exceedances is also a Poisson process and, the cdf of the annual maximum floods is

$F_{Q_{p}}\left(q_{p}\right)=\exp \left\{-\Lambda_{L}\left[G_{Q, L}^{\prime}\left(q_{p}\right)\right]-\Lambda_{H}\left[G_{Q, H}^{\prime}\left(q_{p}\right)\right]\right\}$

where the mean annual number of independent flood events is $\Lambda_{L}$ for L-type and $\Lambda_{H}$ for H-type events. Furthermore, the following relationships hold:

$\Lambda_{q}=\Lambda_{L}+\Lambda_{H}=\Lambda_{p} \exp \left(-\frac{f_{A, L}^{k}}{E\left[i_{A, \tau}^{k}\right]}\right)$

$\Lambda_{H}=\Lambda_{p} \exp \left(-\frac{f_{A, H}^{k}}{E\left[i_{A, \tau}^{k}\right]}\right)$

The flood frequency derived distribution can be written replacing Eqs. (3), (4), (5), (8), (9), (12), (13), (14), (15), (16), (17), (18), (19), (20), (22) and (23) in Eq. (21). Notwithstanding the structural model complexity, the strong difference between the IF and the TCIF distribution is evident by comparing the respective cdf Eqs. (11) and (21). The TCIF distribution includes fifteen parameters: baseflow $\left(q_{o}\right)$, four parameters dependent on basin geomorphology $\left(A, \tau_{A}, \xi, \beta\right)$, four rainfall parameters $\left(E\left[i_{A, \tau}\right], \varepsilon, \Lambda_{p}, k\right)$, and six parameters $\left(f_{A, L}, f_{A, H}, \varepsilon_{L}, \varepsilon_{H}, r_{L}, r_{H}\right)$, which are strictly related to runoff generation mechanisms.

\section{Case studies: climate, geomorphology and land use}

In order to investigate the thresholds effect on the flood probability distribution we used available series of annual maximum floods characterized by high skewness coefficient ( $C a>1.7$, see Table 5). Thus, ten gauged basins in Southern Italy were selected (Table 1 and Fig. 1) with surface area ranging from 15 to $1140 \mathrm{~km}^{2}$. Four out of these ten basins were already included in previous studies (see Fiorentino et al., 2001): 1 Celone at Ponte Foggia San Severo, 2 Venosa at 
Table 1. Climatic and geomorphological descriptors of study basins.

\begin{tabular}{lrrrrrrr}
\hline & $\mathrm{n}$. & $A\left(\mathrm{~km}^{2}\right)$ & $I$ & $C$ & $\Psi$ & $D_{d}$ & $C v_{\text {Itop }}$ \\
\hline Celone at Ponte Foggia San Severo & 1 & 233 & -0.24 & 0.48 & 0.98 & 0.46 & 0.22 \\
Venosa at Ponte Sant' Angelo & 2 & 263 & -0.17 & 0.52 & 0.85 & 0.72 & 0.21 \\
Sinni at Valsinni & 3 & 1140 & 0.57 & 0.40 & 0.41 & 0.58 & 0.23 \\
Basento at Gallipoli & 4 & 853 & 0.28 & 0.52 & 0.40 & 0.52 & 0.22 \\
Alli at Orso & 5 & 46 & 1.26 & 0.32 & 0.98 & 0.81 & 0.22 \\
Corace at Grascio & 6 & 182 & 0.90 & 0.40 & 0.94 & 0.67 & 0.24 \\
Alaco at Mammone & 7 & 15 & 1.66 & 0.26 & 1.00 & 0.31 & 0.18 \\
Tacina at Rivioto & 8 & 79 & 1.43 & 0.31 & 0.97 & 0.91 & 0.22 \\
Trionto at Difesa & 9 & 32 & 0.90 & 0.34 & 0.99 & 0.62 & 0.18 \\
Amato at Marino & 10 & 113 & 0.86 & 0.41 & 0.95 & 0.54 & 0.22 \\
\hline
\end{tabular}

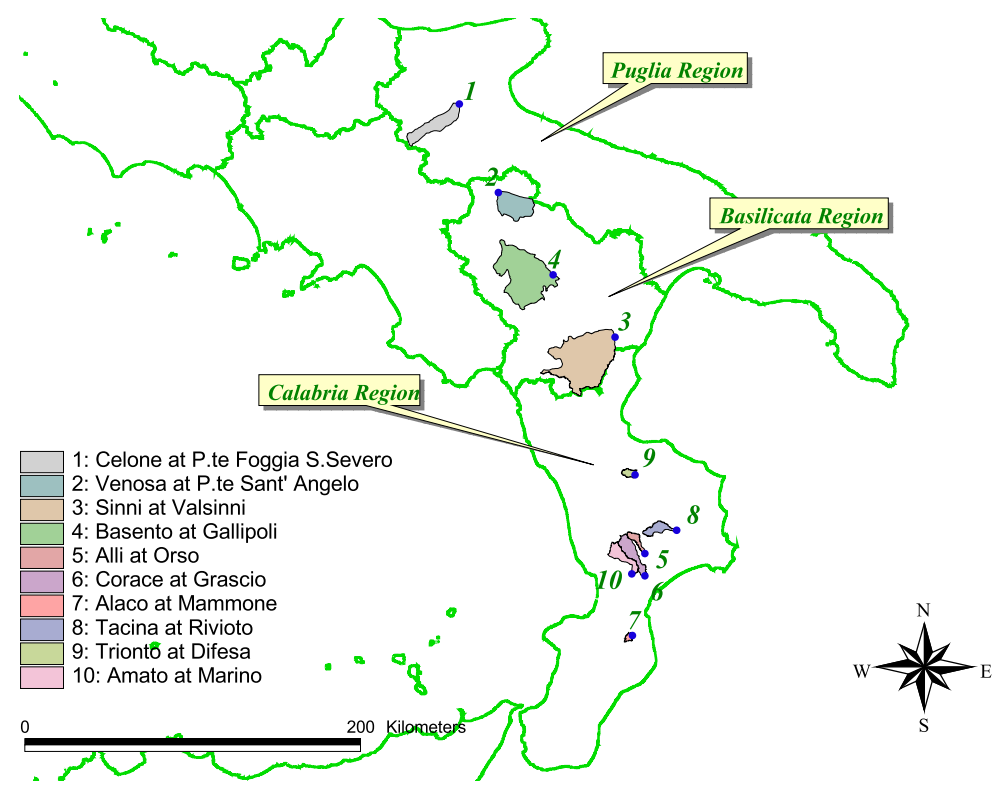

Fig. 1. Study basins in Southern Italy.

Ponte Sant'Angelo, 3 Sinni at Valsinni and 4 Basento at Gallipoli. These basins are located in Basilicata and Puglia. The other basins (5, 6, 7, 8, 9 and 10) are in Calabria. These three regions are quite heterogeneous in climate, geology and land use.

In fact, the north-eastern sector of the entire area (Puglia region in Fig. 1), is characterized by low hills and flatlands where the climate is of the hot-dry Mediterranean type (semiarid or dry sub-humid), with mild, not very rainy winters and warm-dry summers. Moving to the West-Southern sector (Basilicata and Calabria), climate becomes colder and more humid (Southern Appennine).
The mean annual rainfall ranges from around $600 \mathrm{~mm}$ in Puglia to more than $1800 \mathrm{~mm}$ in Basilicata and Calabria. Rainfall and temperature show a typical Mediterranean seasonality. Rainfall in the October-March semester is, on average, more than twice the amount of the period AprilSeptember. The climatic pattern is well reflected by the climatic index (Thornthwaite, 1948):

$I=\frac{h-E_{p}}{E_{p}}$

with $h$ mean annual rainfall and $E_{p}$ mean annual potential 
Table 2. Parameters of the TCIF model.

\begin{tabular}{lrrrrrrrrrrrrrr}
\hline n. & $\Lambda_{L}$ & $\Lambda_{H}$ & $\begin{array}{r}f_{A, L} \\
(\mathrm{~mm} / \mathrm{h})\end{array}$ & $\begin{array}{r}f_{A, H} \\
(\mathrm{~mm} / \mathrm{h})\end{array}$ & $r_{L}$ & $r_{H}$ & $\begin{array}{r}p_{l} \\
(\mathrm{~mm} / \mathrm{h})\end{array}$ & $n$ & $\begin{array}{r}E\left[i_{A, \tau}\right] \\
(\mathrm{mm} / \mathrm{h})\end{array}$ & $\varepsilon$ & $\Lambda_{p}$ & $k$ & $\begin{array}{r}\tau_{A} \\
(\mathrm{~h})\end{array}$ & $\begin{array}{r}q_{o} \\
\left(\mathrm{~m}^{3} / \mathrm{s}\right)\end{array}$ \\
\hline 1 & 5.82 & 0.17 & 2.25 & 8.01 & 0.09 & 0.70 & 23.33 & 0.27 & 1.07 & 0.39 & 44.6 & 0.80 & 5.20 & 2.20 \\
2 & 6.54 & 0.46 & 1.95 & 6.05 & 0.04 & 0.92 & 24.13 & 0.26 & 1.02 & 0.39 & 44.6 & 0.80 & 5.60 & 1.40 \\
3 & 20.59 & 0.41 & 0.00 & 7.32 & 0.16 & 0.50 & 23.13 & 0.40 & 1.50 & 0.33 & 21.0 & 0.80 & 5.60 & 45.00 \\
4 & 8.82 & 0.18 & 0.91 & 7.92 & 0.24 & 0.70 & 21.00 & 0.31 & 1.27 & 0.33 & 21.0 & 0.80 & 4.80 & 25.00 \\
5 & 6.93 & 0.07 & 1.68 & 40.28 & 0.04 & 0.08 & 33.20 & 0.52 & 2.77 & 0.28 & 20.0 & 0.53 & 3.00 & 2.34 \\
6 & 8.57 & 0.43 & 0.68 & 13.18 & 0.16 & 0.40 & 29.80 & 0.45 & 1.88 & 0.28 & 20.0 & 0.53 & 3.80 & 8.84 \\
7 & 6.76 & 0.74 & 0.40 & 25.27 & 0.04 & 0.04 & 39.60 & 0.63 & 7.50 & 0.32 & 10.0 & 0.53 & 1.30 & 0.96 \\
8 & 9.26 & 0.74 & 0.00 & 10.24 & 0.05 & 0.30 & 32.70 & 0.59 & 4.14 & 0.32 & 10.0 & 0.53 & 3.00 & 3.40 \\
9 & 8.82 & 0.18 & 0.96 & 27.49 & 0.02 & 0.10 & 31.00 & 0.50 & 2.65 & 0.28 & 20.0 & 0.53 & 2.80 & 1.17 \\
10 & 6.42 & 0.58 & 1.00 & 9.90 & 0.09 & 0.54 & 28.80 & 0.43 & 1.65 & 0.28 & 20.0 & 0.53 & 4.60 & 5.32 \\
\hline
\end{tabular}

evapotranspiration calculated according to Turc's formula (Turc, 1961) dependent only on mean annual temperature. Eight out of ten selected basins show a positive climatic index indicating humid climate. The other two basins have a negative climatic index which corresponds to arid climate.

Vegetation and land cover patterns are consistent with climate differences and morphological conditions. Arid and semi-arid zones are characterized by scarce vegetation, which gradually turns into shrub and bush formations, wheat crops and pasture land, to finally reach woodlands and forests in humid and hyper-humid areas of the Southern Apennine mountains.

Different lithological units are recognized showing characters of permeability of different type and degree. In fact, sediments and rocks, permeable because of porosity and fissuring, can be distinguished. In some areas the system also shows communicating cracks like bedding joints, faults, and intense circulation of groundwater. SubAppennine clays and flysch formations are also present with interbedding of marls and sandstones.

Such variability is properly described in Table 1 which reports climatic index $(I)$, basin area $(A)$, runoff coefficient $(C)$, permeability index $(\psi)$, drainage density $\left(D_{d}\right)$, and coefficient of variation of topographic index $\left(C v_{\text {Itop }}\right)$ of study basins. Drainage density was calculated as the total network length divided by the entire basin area.

All geomorphological descriptors $\left(A, C, \psi, D_{d}, C v_{\text {Itop }}\right)$ reported in Table 1 were computed in a GIS using maps of geology, pedology, land cover, local slope and a digital elevation model (DEM) of Southern Italy. For basins in Puglia and Basilicata values of $C, \psi$, and $C v_{\text {Itop }}$ were evaluated by Fiorentino and Iacobellis (2001) and Fiorentino at al. (2003). For all other values we used the Corine Land-Cover 2000 map, geological maps (scale 1:50000), DEM $(250 \mathrm{~m})$, and pedological maps produced at the scale 1:100 000 .

\section{Model application}

All the model parameters, which were listed in Sect. 3, have a clear physical meaning and much about their behaviour is known from previous applications of the IF model. The six parameters representative of the role of runoff thresholds $\left(f_{A, L}, f_{A, H}, \varepsilon_{L}, \varepsilon_{H}, r_{L}, r_{H}\right)$ will be particularly focused in this section. In order to understand their behaviour, the model was applied to gauged basins, thus exploiting the available time series of annual maximum floods. Then, the model was first tested evaluating its descriptive ability. Best-fit estimates of the six parameters were obtained for each basin and their dependence on climatic and geomorphological descriptors was explored. Also, a conceptual model validation was obtained by analyzing the consistency of parameters regional patterns with the dominant hydrological processes. These analyses and results are described in Sect. 5.2 while Sect. 5.1 reports the estimation of rainfall parameters. Regarding the other model parameters, the values of $\beta=4$ and $\xi=0.7$ were assigned following Iacobellis and Fiorentino (2000); basin area and lag-time were available in previous studies (Iacobellis and Fiorentino, 2001; Iacobellis et al., 2002); the base flow $q_{o}$ was estimated as the average monthly flow measured at-site in January and February (see Table 2).

\subsection{Estimation of rainfall parameters}

Parameters dependent on rainfall $\left(E\left[i_{A, \tau}\right], \varepsilon, \Lambda_{p}, k\right)$ were estimated, for each basin, exploiting regional frequency analysis of annual maximum rainfall.

According to a compound Poisson process, if a variable (base process) is Weibull distributed and its rate of occurrences is Poisson distributed, the distribution of the annual maxima turns out to be a Power Extreme Value (PEV) (Villani, 1993). Then, a regional estimation procedure, based on the PEV distribution and on the maximum likelihood 

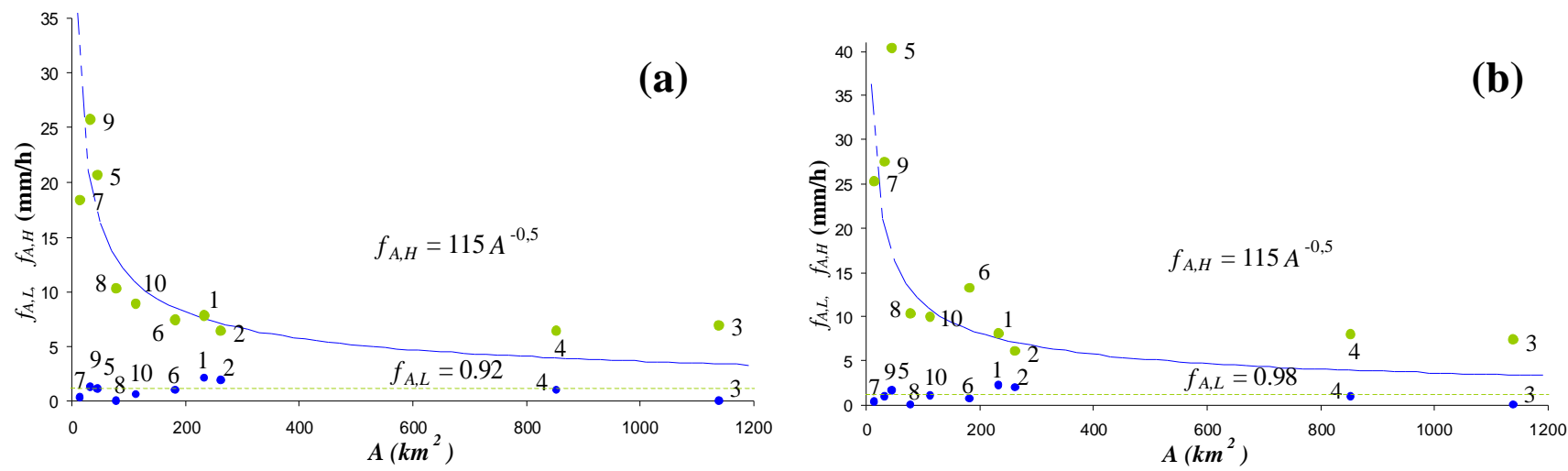

Fig. 2. Runoff thresholds scaling law with basin area; (a) estimated by TCEV distribution; (b) estimated by TCIF distribution.

method (ML), was applied to 403 annual maximum daily rainfall series in order to evaluate the exponent $k$ of the Weibull distribution of rainfall intensity. Regional values of $k$ equal to 0.8 in Puglia and Basilicata (Fiorentino and Iacobellis, 2001) and 0.53 in Calabria (Claps et al., 2000) were found.

According to the same compound Poisson process, the relationship between the averages of the annual maxima and of the base process is known. Thus, the expected value of spacetime average rainfall intensity $E\left[i_{A, \tau}\right]$, in the total basin area $A$ and duration $\tau_{A}$, may be evaluated as:

$$
E\left[i_{A}\right]=\frac{p_{1} \tau_{A}^{n-1}\left[1-\exp \left(-1.1 \tau_{A}^{0.25}\right)+\exp \left(-1.1 \tau_{A}^{0.25}-0.004 A\right)\right]}{\Lambda_{p} \sum_{j=0}^{\infty} \frac{(-1)^{j} \Lambda_{p}^{j}}{j !(j+1)^{(1 / k+1)}}}
$$

in which the US Weather Bureau areal reduction factor is used (see Eagleson, 1972), $\Lambda_{p}$ is the mean annual number of independent rainfall events, $p_{1}$ and $n$ (Table 2) are the parameters of the intensity-duration-frequency (IDF) curve of the expected annual maximum rainfall intensity (Table 2).

We used also regional estimates of $\varepsilon$ and $\Lambda_{p}$, given by Fiorentino and Iacobellis (2001) and Claps et al. (2000), and reported in Table 2.

\subsection{Evaluation of parameters dependent on runoff} thresholds and model results

By means of Eqs. (22) and (23) it is possible to replace $f_{A, L}$ and $f_{A, H}$ in, respectively, Eqs. (15) and (16). In this way, the derived distribution can be expressed using the following six parameters dependent on runoff thresholds: $\Lambda_{L}, \Lambda_{H}, \varepsilon_{L}$, $\varepsilon_{H}, r_{L}, r_{H}$.

\subsubsection{Scaling factors $\varepsilon_{L}, \varepsilon_{H}$}

The TCIF distribution arises, in Eq. (21), as a two component compound Poisson distribution as well as the TCEV distribution (Rossi et al., 1984). The TCEV distribution has four parameters, $\Lambda_{1}, \theta_{1}, \Lambda_{2}, \theta_{2}$, and its cumulative distribution function is

$F_{Q_{p}}\left(q_{p}\right)=\exp \left[-\Lambda_{1} \exp \left(-{ }^{q_{p}} / \theta_{1}\right)-\Lambda_{2} \exp \left(-{ }^{q_{p}} / \theta_{\theta_{2}}\right)\right] ;$

with $\theta_{2}>\theta_{1}>0$, and $\Lambda_{1}>\Lambda_{2}>0$. Using the annual maximum flood series we obtained, via maximum likelihood, at-site estimates of TCEV parameters, for each basin. Then, assuming $\Lambda_{L}=\Lambda_{1}$ and $\Lambda_{H}=\Lambda_{2}$, we found the threshold values $f_{A, L}$ and $f_{A, H}$ by means of Eqs. (22) and (23). Results are reported in Table 3. Figure 2a shows that each runoff threshold scales with area according to a power law with exponent $\varepsilon_{L}=0$ and $\varepsilon_{H}=0.5$, respectively.

Such scaling relationships confirm the existence of significant regional patterns of the above defined runoff thresholds as observed by Fiorentino and Iacobellis (2001). It is important to highlight that these results were obtained by means of a model-independent estimation of parameters $\Lambda_{L}, \Lambda_{H}$ based on the use of the TCEV distribution. Then, the different scaling behaviour of the thresholds allows to characterize the two processes:

- the L-type (frequent) response occurs when rainfall intensity exceeds a constant infiltration rate (1st threshold) in the source area $a_{L}$;

- the H-type (rare) response occurs when rainfall depth exceeds a storage capacity ( 2 nd threshold) in the source area $a_{H}$. 
Table 3. Parameters of the TCEV model.

\begin{tabular}{lrrrrrr}
\hline n. & $\Lambda_{1}$ & $\Theta_{1}$ & $\Lambda_{2}$ & $\begin{array}{r}\Theta_{2} \\
(\mathrm{~mm} / \mathrm{h})\end{array}$ & $\begin{array}{r}f_{A, L} \\
(\mathrm{~mm} / \mathrm{h})\end{array}$ & $f_{A, H}$ \\
\hline 1 & 6.61 & 15.64 & 0.19 & 67.93 & 2.07 & 7.83 \\
2 & 6.74 & 11.10 & 0.38 & 103.41 & 1.93 & 6.35 \\
3 & 20.51 & 127.52 & 0.49 & 481.35 & 0.00 & 6.90 \\
4 & 8.33 & 110.11 & 0.38 & 337.22 & 0.95 & 6.34 \\
5 & 8.18 & 4.94 & 0.38 & 18.43 & 1.13 & 20.67 \\
6 & 6.52 & 39.63 & 1.19 & 114.14 & 0.95 & 7.37 \\
7 & 6.65 & 3.23 & 1.11 & 11.29 & 0.31 & 18.33 \\
8 & 8.90 & 6.52 & 1.10 & 85.15 & 0.00 & 10.24 \\
9 & 7.75 & 2.26 & 0.21 & 19.05 & 1.26 & 25.75 \\
10 & 8.30 & 11.71 & 0.70 & 102.90 & 0.60 & 8.92 \\
\hline
\end{tabular}

In fact, we referred to the phenomenological interpretation provided by Fiorentino and Iacobellis (2001), which is here briefly resumed. In a simple scheme, if the runoff threshold corresponds to a constant storage depth $W$, the average infiltration rate in the critical duration $\tau_{a}$ is:

$f_{a}=\frac{W}{\tau_{a}} \propto a^{-0.5}$.

Thus, the threshold scales with $a$ with a power law with exponent -0.5 as well as the lag-time $\tau_{a}$ scales with $a$ according to a power law with exponent 0.5 (Viparelli, 1963; Troutman and Karlinger, 1984; Iacobellis et al., 2002). Otherwise, if the runoff threshold corresponds to the gravitational infiltration rate $c$,

$f_{a}=\frac{c \tau_{a}}{\tau_{a}}=c$.

Hence the threshold rainfall intensity is constant and the scaling exponent can be assumed equal to 0. Reasonably, Eq. (27) holds in areas where the expected antecedent soil moisture condition is dry while Eq. (28) holds in areas with wet antecedent soil moisture condition. For further details about this rationale the reader is kindly addressed to Fiorentino and Iacobellis (2001; Sect. 5).

\subsubsection{Parameters $\Lambda_{L}, \Lambda_{H}, r_{L}, r_{H}$}

According to the findings reported in Sect. 5.2.1, we assumed $\varepsilon_{L}=0$ in Eq. (15) and $\varepsilon_{H}=0.5$ in Eq. (16). Then, for the estimation of parameters $\Lambda_{L}, \Lambda_{H}, r_{L}, r_{H}$, an at-site estimation procedure was implemented based on generation of synthetic time series of annual maximum floods. For each study basin the following procedure was repeated. A number of datasets of four values $\left(\Lambda_{L}, \Lambda_{H}, r_{L}, r_{H}\right)$ was prepared in which all possible combinations of these parameters values were given. We uniformly sampled the parameter space considering, for each of the parameters $\Lambda_{L}, \Lambda_{H}, r_{L}, r_{H}$, values ranging from a minimum to a maximum with a constant step
Table 4. Maximum, minimum and step values used in generation of synthetic time series.

\begin{tabular}{llll}
\hline & Minimum & Maximum & Step \\
\hline$r_{L}$ & 0.01 & 0.50 & 0.01 \\
$r_{H}$ & $r_{L}$ & 0.99 & 0.01 \\
$\Lambda_{L}$ & $\Lambda_{1}-5$ & $\min \left(\Lambda_{1}+5, \Lambda_{p}-\Lambda_{H}\right)$ & 0.01 \\
$\Lambda_{H}$ & 0.01 & $\min \left(\Lambda_{2}+1, \Lambda_{p}-\Lambda_{L}\right)$ & 0.01 \\
\hline
\end{tabular}

(Table 4). In particular, $r_{L}$ ranges from 0.01 to $0.5 ; r_{H}$ ranges from $r_{L}$ (thus satisfying the condition $r_{H} / r_{L} \geq 1$ ) to 0.99 ; $\Lambda_{L}$ and $\Lambda_{H}$ range in intervals around their TCEV-ML estimates (see Sect. 5.2.1 and Table 3). More precisely, $\Lambda_{L}$ ranges from $\Lambda_{1}-5$ to $\Lambda_{1}+5$ (or $\Lambda_{p}-\Lambda_{H}$ if $\Lambda_{1}+\Lambda_{H}+5>\Lambda_{p}$ as it happens for basin \#3), and $\Lambda_{H}$ from 0.01 to $\Lambda_{2}+1$ (or $\Lambda_{p}-\Lambda_{L}$ if $\Lambda_{L}+\Lambda_{2}+1>\Lambda_{p}$ ). In other words, in order to satisfy the conditions $\Lambda_{H}+\Lambda_{L} \leq \Lambda_{p}$ and $\Lambda_{H} / \Lambda_{L} \leq 1$, the maximum value of $\Lambda_{L}$ is set equal to the minimum between $\Lambda_{1}+5$ and $\Lambda_{p}-\Lambda_{H}$, while the maximum value of $\Lambda_{H}$ is set equal to the minimum between $\Lambda_{2}+1$ and $\Lambda_{p}-\Lambda_{L}$ (see Table 4). For each parameters dataset, a synthetic time series of 5000 TCIF-distributed random numbers was generated. The selected parameters dataset was chosen as the one generating the synthetic time series with the minimum euclidean distance, in the space of mean, coefficient of variation and coefficient of skewness, to the observed time series of annual maximum floods.

\subsubsection{Results}

Table 5 displays mean $(\mu)$, coefficient of variation $(C v)$ and coefficient of skewness $(\mathrm{Ca})$ of the annual maximum floods and of the synthetic time series generated by the selected parameter set. For mere comparison we show the same descriptive statistics obtained by the TCEV distribution, too.

The TCIF distribution shows good performances in terms of descriptive ability. The visual comparison of the TCIF cdf and the Weibull plotting positions of the annual maximum flood series is reported in Fig. 3 for all basins. With particular reference to the Matalas condition of separation, the skewness of the annual maximum flood distributions is always captured by the TCIF distribution as confirmed by the analytical comparison shown in Table 5 .

We estimated the threshold values $f_{A, L}$ and $f_{A, H}$ by means of the TCIF estimates of $\Lambda_{L}, \Lambda_{H}$, and Eqs. (22) and (23). Results are shown in Table 2 and Fig. 2b. Once again, their behaviour is consistent with scaling laws Eqs. (15) and (16) with exponents $\varepsilon_{L}=0$ and $\varepsilon_{H}=0.5$.

This results confirm that, in the study basins, two thresholds are identified. Each has a peculiar scaling behaviour that properly reflects the process mechanism described in Sect. 5.2.1. 

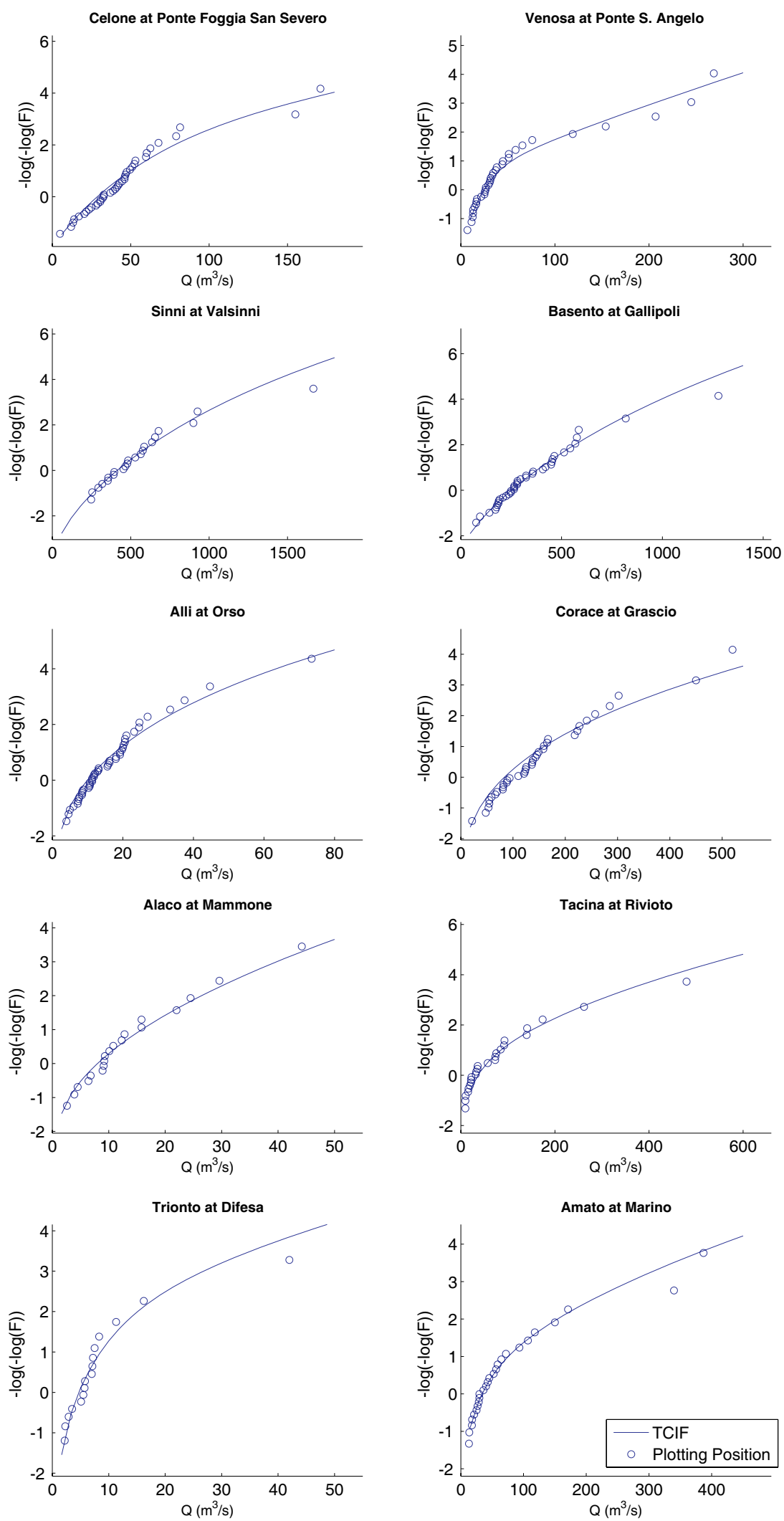

Fig. 3. Gumbel probability plots of TCIF distribution and Weibull plotting positions of annual maximum flood series recorded in study basins. 
Table 5. Descriptive statistics of annual maximum flood series.

\begin{tabular}{rrrrrrrrrrr}
\hline & \multicolumn{3}{c}{ Study basins } & \multicolumn{4}{c}{ TCEV distribution } & \multicolumn{3}{c}{ TCIF distribution } \\
\hline n. & n. obs. & $\mu$ & $C v$ & $C a$ & $\mu$ & $C v$ & $C a$ & $\mu$ & $C v$ & $C a$ \\
\hline 1 & 39 & 45.70 & 0.72 & 2.43 & 46.01 & 0.67 & 1.98 & 45.62 & 0.76 & 1.94 \\
2 & 34 & 55.84 & 1.18 & 2.26 & 54.54 & 1.15 & 2.39 & 55.87 & 1.09 & 2.20 \\
3 & 22 & 554.91 & 0.56 & 2.42 & 545.89 & 0.51 & 2.07 & 555.79 & 0.52 & 1.82 \\
4 & 38 & 352.61 & 0.63 & 2.25 & 347.94 & 0.59 & 1.89 & 352.80 & 0.62 & 1.86 \\
5 & 47 & 16.66 & 0.72 & 2.74 & 16.59 & 0.66 & 2.34 & 16.66 & 0.82 & 2.35 \\
6 & 38 & 151.65 & 0.70 & 1.83 & 149.16 & 0.67 & 1.63 & 143.65 & 0.81 & 1.72 \\
7 & 19 & 13.61 & 0.75 & 1.76 & 13.78 & 0.73 & 1.61 & 13.61 & 0.81 & 1.62 \\
8 & 25 & 81.16 & 1.27 & 2.79 & 80.85 & 1.11 & 1.94 & 81.21 & 1.17 & 2.83 \\
9 & 16 & 8.73 & 1.09 & 3.18 & 8.36 & 0.99 & 3.05 & 8.53 & 0.99 & 2.90 \\
10 & 26 & 79.19 & 1.18 & 2.43 & 78.44 & 1.10 & 2.24 & 79.21 & 1.11 & 2.38 \\
\hline
\end{tabular}
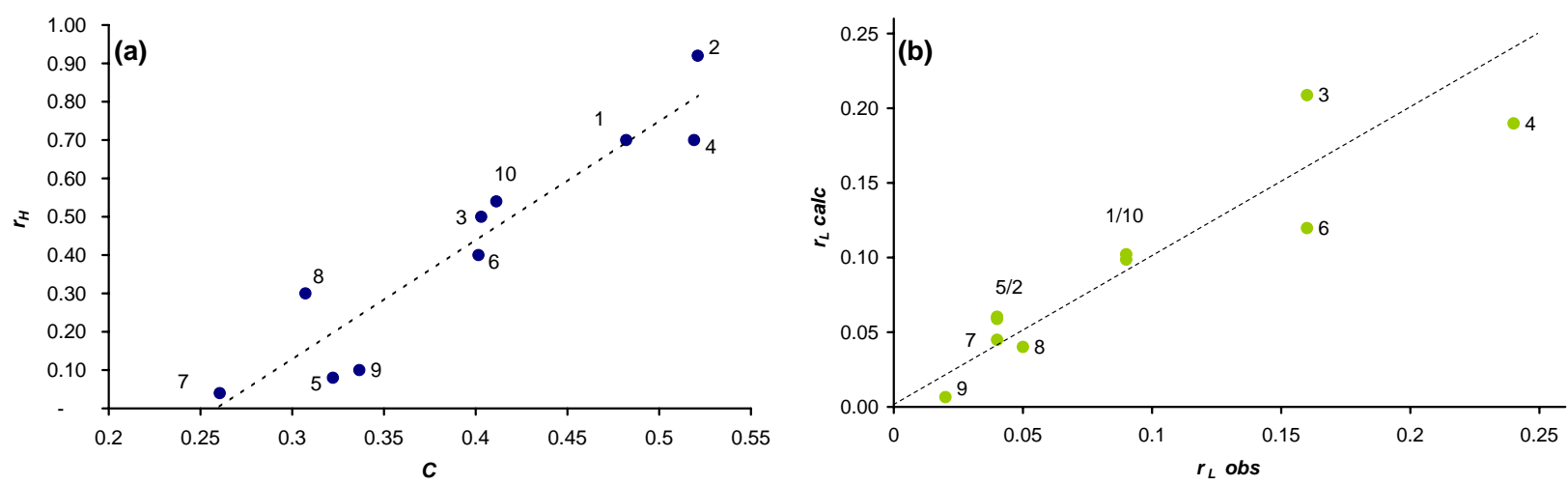

Fig. 4. (a) regional relationship between H-type contributing area ratio $r_{H}$ and runoff coefficient $C$; (b) L-type contributing area ratios $r_{H}$ vs. multiple regression estimates based on permeability index, drainage density and variation coefficient of the topographic index $C v_{\text {Itop }}$.

Further analyses were carried out to assess physical controls on model parameters $r_{L}$ and $r_{H}$. We analyzed the regional patterns of the $r_{L}$ and $r_{H}$ estimates and found a significant dependence on the geomorphological descriptors listed in Sect. 4. In particular, $r_{H}$ ranges between 0.04 and 0.70 and is linearly related to the runoff coefficient $C$ confirming that this type of runoff mainly depends on soil, slope and land cover (Fig. 4a).

$$
r_{H}=3.12 C-0.81 \quad R^{2}=0.89
$$

It is relevant that an analogous dependency was observed by Fiorentino et al. (2003) only in arid basins of the same regions with the IF (one component) model. On the other hand, the L-type (frequent) contributing area ratio $r_{L}$ ranges between 0.02 and 0.24 . Results of multiple regression analysis show that $r_{L}$ depends on the permeability index, $\psi$, the drainage density, $D_{d}$ and the variation coefficient of the topographic index $C v_{\text {Itop }}$ (Fig. 4b):

$r_{L}=-0.145 D_{d}-0.164 \psi+1.99 C v_{\text {Itop }}-0.10 R^{2}=0.83$

In other terms the average contributing area decreases for higher values of bedrock permeability and drainage density while it increases for higher values of variation coefficient $\left(C v_{\text {Itop }}\right)$ of the topographic index. Even in this case results confirm findings of Fiorentino et al. (2003) in humid basins of Puglia and Basilicata with the IF (one component) model. Moreover a dependence on permeability and drainage density emerges which was never before observed in humid basins. This significant dependence is probably due to the heterogeneous behaviour of basins in Calabria (5, 6, 7, 8, 9 and 10) that were not considered in previous applications of the IF model. 


\section{Conclusions}

In this work a simple analytical scheme for flood frequency derived distribution, that includes two different thresholddriven mechanisms of runoff generation, is used in order to explain highly skewed annual maximum flood distributions. Particular insights are provided into dynamics of source areas by revealing the scaling behaviour of non-linear runoff thresholds. The research also focus on interactions between climatic, topographic, geologic, soil, and other landscape properties with flood frequency distributions.

We started from the basic consideration that, depending on geology, pedology and landuse factors, storage capacity can be exceeded, in both humid and arid climates, only during rather rare storms. Nevertheless it sometimes happens that, depending on soil moisture conditions and on dynamics of sub-surface flow, also less intense rainfall intensity may produce a significant flood peak.

Then, in analogy with the theory behind the TCEV distribution (Rossi et al., 1984), we introduced two different threshold mechanisms as responsible of ordinary and extraordinary events. The first one is characterized by frequent occurrences (higher mean annual number $\Lambda$ ) and lower average of exceedances. The second one produces rare events (lower $\Lambda$ ) and higher average of exceedances. We implemented a two component derived distribution model (TCIF), which generalizes the derived distribution proposed by Iacobellis and Fiorentino (2000). The model is based on the simple rationale that ordinary floods are produced by less severe storms insisting on relatively small contributing areas displaced along the river network. The extra-ordinary floods arise when a large part of the basin area contributes to runoff with high net rainfall intensity.

The model was applied to 10 gauged basins in Southern Italy characterized by high coefficient of skewness. For each basin the fifteen model parameters were estimated. Ten out of fifteen parameters were estimated using rainfall data and geomorphologic information. We estimated the base flow using available records of measured stream discharge and exploited the recorded series of annual maximum flood series in order to better characterize the six parameters dependent on runoff thresholds.

The TCIF distribution provided good performances in terms of descriptive ability as shown in Table 5 and Fig. 3.

One of the main results, provided by different estimation procedures, regards the scaling behaviour of the runoff thresholds. In Sect. 5.2.1, in fact, the runoff thresholds are estimated, for each basin, under the following hypotheses: (i) rainfall intensity is Weibull distributed, (ii) the rate of occurrences of runoff thresholds exceedances is Poisson distributed, (iii) the annual maximum floods are TCEV distributed. Analogous results are obtained by using the TCIF model in Sect. 5.2.2. They show that Eqs. (15) and (16) actually hold with exponents close to values of $\varepsilon_{L}=0$ and $\varepsilon_{H}=0.5$.
These findings reveal that floods are produced by two different mechanisms that coexist in both arid and humid climates. Moreover, these relationships (see Fig. 2) allow to characterize the runoff thresholds and recognize their behaviour with respect to consolidated hydrological schemes. In fact, the scaling behaviour of the H-type (rare) runoff threshold corresponds to a storage threshold while the L-type (frequent) runoff threshold corresponds to a constant infiltration rate. Thus, the H-type (rare) response arises, in both arid and humid basins, only when an intense and persistent rainfall of significant areal extension produces runoff by exceeding a water storage capacity over large and more or less vegetated hillslopes. On the other hand the L-Type (frequent) response could be associated to a saturation excess mechanisms. In fact source areas by saturation excess arise when the water table intercepts the land surface and expands while rainfall intensity recharges the shallow groundwater. Therefore rainfall intensity must be greater than the constant infiltration rate which drains, in a dynamic equilibrium, the shallow groundwater through the saturated soil-bedrock system. This mechanism usually dominates in humid areas where frequent rainfall and subsurface flow almost continuously recharge a shallow groundwater underlying the river streams. This is confirmed for humid basins 3 and 4 that according to Fiorentino and Iacobellis (2001) showed a saturation excess dominant mechanism when studied with a single component model. Nevertheless, a saturation excess mechanism, in particular conditions, may also occur in arid or semi-arid basins (e.g. Kirkby, 1997; Calvo-Cases et al., 2003; Lange et al., 2003; Dagés et al., 2008, among many others). In fact, even in arid zone, with sparsely vegetated hillslopes, there is generally a concentration of vegetation in the catchment drainage system. Here saturation-excess may produce (at least seasonally) soil saturation via a high water table or lateral water movement above an impeding horizon due to soil-bedrock low permeability. This is the case of basin \#1 $(I=-0.24)$ where a deep and very fine textured clay soil surrounds most of the river network. Also in basin \#2 $(I=-0.17)$ a bedrock with low permeability formed by lake deposits of piroclastic sediments and alluvial deposits of fine texture lies beneath the entire river network. In both basins ordinary floods seem to be originated by not severe storms insisting on the less permeable portion of the basin while the remaining (greater) surface contributes only when precipitation depth is enough to exceed the storage capacity of a larger source area.

This interpretation of results is of particular interest within the ongoing research about thresholds dynamics in the hydrological processes. In particular, it is apparently contrasting with the hypotheses assumed by McGrath et al. (2005) which use a threshold rainfall intensity for infiltration excess and a threshold storage for saturation excess. Nevertheless one has to recognize that their runoff thresholds are used in a marked Poisson process with instantaneous rainfall events combined with a lumped water balance model while our runoff threshold are referred to rainfall events of 
critical duration equal to the lag-time $\tau_{a}$ and they represent an infiltration rate averaged in space (over the contributing area a) and in time (over the lag time $\tau_{a}$ ).

On the other hand we find good agreement with Sivapalan et al. (1990) and Sivapalan et al. (2005) that observed a change of dominant runoff processes from saturation excess to infiltration excess with increasing return period. In fact, consistently with the associated runoff generation mechanisms and with previous results of Fiorentino and Iacobellis (2001) we found that:

- the L-type (frequent) contributing area ratio $r_{L}$ has a much smaller regional range (from 0.02 to 0.24 ) and depends (Eq. 30) on the permeability index $\psi$, the drainage density $D_{d}$ and the variation coefficient of the topographic index $C v_{\text {Itop }}$;

- the H-type (rare) contributing area ratio $\left(r_{H}\right)$ shows a wide variability between different basins (from 0.04 to 0.70 ) and is linearly related (Eq. 29) to the runoff coefficient $C$ which depends on soil type, land cover and local slope.

These regional relationships (see also Fig. 4a and b) also support the idea that measurable basins features may help in characterize the basin response type.

All these results are of particular interest in the framework of regional flood frequency analysis. In fact they suggest that important characteristics (including high skewness) of the annual maximum flood distribution can be ascribed to particular physical controls. In other words, an attempt is made to enhance knowledge on spatial heterogeneity of flood distribution skewness and its dependence on climatic and geomorphological characteristics of real basins. It is well known that available at-site estimation techniques, with particular regard to parameters dependent on the second and third order moments, are not recommended for short data series, because of the very high estimator variability. Thus, an improved ability to recognize the parameters spatial variability would offer important perspectives in regional flood frequency analysis.

Hence, an effort is made to provide a theoretical framework, in the field of long-medium term flood prediction in ungauged basins, less prone to quality and length of discharge data and more suitable for the exploitation of satellite data and ground-based ancillary data.

Thus further research on runoff thresholds is required and deeper insights are expected by the contextual use of virtual laboratories (e.g. continuous simulation models), field experiments and earth monitoring.

Acknowledgements. Authors gratefully acknowledge the support of MIUR (Italian Ministry of Instruction, University and Research) under the grant PRIN CoFin2005 entitled "Climate-soil-vegetation interaction in hydrological extremes". Authors would like also to thank M. Sivapalan, J. Parajka and three anonymous referees for their constructive suggestions.

Edited by: M. Sivapalan

\section{References}

Beven, K. J.: Towards the use of catchment geomorphology in flood frequency predictions, Earth Surf. Proc. Land., 12, 6-82, 1987.

Beven, K. J. and Kirkby, M. J.: A physically-based variable contributing area model of basin hydrology, Hydrol. Sci. B., 24(1), 43-69, 1979.

Blazkova, S. and Beven, K. J.: Flood frequency estimation by continuous simulation for a catchment treated as ungauged (with uncertainty), Water. Resour. Res., (38)8, 1-14, 2002.

Bras, R. L., Gaboury, D. R., Grossman, D. S., and Vicen, G. J.: Spatially varying rainfall and flood risk analysis, J. Hydraul. Eng.ASCE , 111, 754-773, 1985.

Calvo-Cases, A., Boix-Fayos, C., and Imeson, A. C.: Runoff generation, sediment movement and soil water behaviour on calcareous (limestone) slopes of some Mediterranean environments in southeast Spain, Geomorphology, 50, 1-3, 269-291, 2003.

Claps, P., Fiorentino, M., and Iacobellis, V.: Regional flood frequency analysis with a theoretically derived distribution function, Proc. of the EGS Plinius Conference on Mediterranean Storms, 341-352, 2000.

Consuegra, D., Meylan, P., and Musy, A.: A probabilistic approach to estimate design parameters for flood control projects, in: Engineering Hydrology, edited by: Kuo, C. Y., ASCE, San Francisco, 455-460, 1993.

Cunnane, C.: Review of statistical models for flood frequency estimation, Proc. of the Int. Symp. on Flood Frequency and Risk Analysis, Louisiana State University, Baton Rouge, USA, 1986.

Dagès, C., Voltz, M., Lacas, J. G., Huttel, O., Negro, S., and Louchart, X.: An experimental study of water table recharge by seepage losses from a ditch with intermittent flow, Hydrol. Process., 22(18), 3555-3563, 2008.

De Michele, C. and Salvadori, G.: On the derived flood frequency distribution: analytical formulation and the influence of antecedent soil moisture condition, J. Hydrol., 262, 245-258, 2002.

De Smedt, F., Yongbo, L., and Gebremeskel, S.: Hydrologic modelling on a catchment scale using GIS and remote sensed land use information, edited by: Brebbia, C. A., Risk Analysis II, WIT press, Southampton, Boston, 295-304, 2000.

Eagleson, P. S.: Dynamics of flood frequency, Water Resour. Res., 8(4), 878-898, 1972.

Fiorentino, M., Rossi, F., and Villani, P.: Effect of the basin geomorphoclimatic characteristics on the mean annual flood reduction curve, Proc. of the 18th Annual Conference on Modeling and Simulation, Pittsburgh, part 5, 1777-1784, 1987.

Fiorentino, M. and Iacobellis, V.: Non-linearity in the process of floods generation, Proc. of the EGS Plinius Conference, 269276, 2000. 
Fiorentino, M. and Iacobellis, V.: New insights about the climatic and geologic control on the probability distribution of floods, Water Resour. Res., 37(3), 721-730, 2001.

Fiorentino, M., Carriero, D., Laguardia, G., Manfreda, S., Margiotta, M., Rosano, R., Sole, A., and Iacobellis, V.: Una proposta metodologica per la mappatura della variabilità spaziale delle perdite idrologiche durante i fenomeni di piena, Proc. of "Convegno Nazionale sulla Conservazione dell'ambiente e rischio idrogeologico", CNR-GNDCI n. 2830, 147-154, 2003.

Fiorentino, M., Manfreda, S., and Iacobellis, V.: Peak runoff contributing area as hydrological signature of the probability distribution of floods, Adv. Water Resour., 30, 2123-2134, 2007.

Franchini, M., Galeati, G., and Lolli, M.: Analytical derivation of the flood frequency curve through partial duration series analysis and a probabilistic representation of the runoff coefficient, $\mathrm{J}$. Hydrol., 303, 1-15, 2005.

Goel, N. K., Kurothe, R. S., Mathur, B. S., and Vogel, R. M.: A derived flood frequency distribution for correlated rainfall intensity and duration, J. Hydrol., 228, 56-67, 2000.

Gottschalk, L. and Weingartner, R.: Distribution of peak flow derived from a distribution of rainfall volume and runoff coefficient, and a unit hydrograph, J. Hydrol., 208, 148-162, 1998.

Haan, C. T. and Edwards, D. R.: Joint probability estimates of return period flows, Transactions of the American Society of Agricultural Engineers, 31(4), 1115-1119, 1988.

Iacobellis, V. and Fiorentino, M.: Derived distribution of floods based on the concept of partial area coverage with a climatic appeal, Water Resour. Res., 36(2), 469-482, 2000.

Iacobellis, V., Claps, P., and Fiorentino, M.: Climatic control on the variability of flood distribution, Hydrol. Earth Syst. Sci., 6, 229238, 2002, http://www.hydrol-earth-syst-sci.net/6/229/2002/.

Kirkby, M. J.: Topmodel: a personal view, Hydrol. Proc., 11, 10871097, 1997.

Kurothe, R. S., Goel, N. K., Mathur, B. S.: Derived flood frequency distribution for negativaly correlated rainfall intensity and duration, Water Resour. Res., 33(9), 2103-2107, 1997.

Kusumastuti, D. I., Struthers, I., Sivapalan, M., and Reynolds, D. A.: Threshold effects in catchment storm response and the occurrence and magnitude of flood events: implications for flood frequency, Hydrol. Earth Syst. Sci., 11, 1515-1528, 2007. http://www.hydrol-earth-syst-sci.net/11/1515/2007/.

Lange, J., Greenbaum, N., Husary, S., Ghanem, M., Leibundgut, C., and Schick, A. P., Runoff generation from successive simulated rainfalls on a rocky, semi-arid, Mediterranean hillslope, Hydrol. Process., 17(2), 279-296, 2003.

Loukas, A.: Flood frequency estimation by a derived distribution procedure, J. Hydrol., 255, 69-89, 2002.

Lu, L. and Stedinger, J. R.: Sampling variance of normalized GEV/PWM quantile estimators and a regional homogeneity test, J. Hydrol., 138, 223-245, 1992.

Manfreda, S., Fiorentino, M., and Iacobellis, V.: DREAM: a distributed model for runoff, evapotranspiration, and antecedent soil moisture simulation, Adv. Geosci., 2, 31-39, 2005, http://www.adv-geosci.net/2/31/2005/.
Matalas, N. C., Slack, J. R., and Wallis, J. R.: Regional skew in search of a parent, Water Resour. Res., 11(6), 815-826, 1975.

McGrath, G. S., Hinz, C., and Sivapalan, M.: Temporal dynamics of hydrological threshold events, Hydrol. Earth Syst. Sci., 11, 923 938, 2007, http://www.hydrol-earth-syst-sci.net/11/923/2007/.

Muzik, I.: The method of derived distributions applied to peak flows, in: Engineering Hydrology, edited by: Kuo, C. Y., ASCE, San Francisco, 437-442, 1993.

Raines, T. H. and Valdes, J. B.: Estimation of flood frequencies for ungauged catchments, J. Hydraul. Eng.-ASCE , 119(10), 11381154, 1993.

Rossi, F., Fiorentino, M., and Versace, P.: Two component extreme value distribution for flood frequency analysis, Water Resour. Res., 20(7), 847-856, 1984.

Sivapalan, M., Blöschl, G., Merz, R., and Gutknecht, D.: Linking flood frequency to long-term water balance: Incorporating effects of seasonality, Water Resour. Res., 41, W06012, doi:10.1029/2004WR003439, 2005.

Sivapalan, M., Takeuchi, K., Franks, S. W., Gupta, V. K., Karambiri, H., Lakshmi, V., Liang, X., McDonnell, J. J., Mendiondo, E. M., O'Connell, P. E., Oki, T., Pomeroy, J. W., Schertzer, D., Uhlenbrook, S. and Zehe, E.: IAHS Decade on Predictions in Ungauged Basins (PUB), 2003-2012: Shaping an exciting future for the hydrological sciences, Hydrolog. Sci. J., 48(6), 857-880, 2003.

Sivapalan, M., Wood, E. F., and Beven, K. J.: On hydrologic similarity, 3, A dimensionless flood frequency model using a generalized geomorphologic unit hydrograph and partial area runoff generation, Water Resour. Res., 26(1), 43-58, 1990.

Struthers, I. and Sivapalan, M.: A conceptual investigation of process controls upon flood frequency: role of thresholds, Hydrol. Earth Syst. Sci., 11, 1405-1416, 2007, http://www.hydrol-earth-syst-sci.net/11/1405/2007/.

Thornthwaite, C. W.: An approach toward a rational classification of climate, Geogr. Rev., 38, 55-94, 1948.

Troutman, B. M. and Karlinger, M. R.: Unit hydrograph approximations assuming linear flow through topologically random channel networks, Water Resour. Res., 21, 743-754, 1984.

Turc, L.: Estimation of irrigation water requirements, potential evapotranspiration: a simple climatic formula evolved up to date, Annals of Agronomy, 12, 13-14, 1961.

Veneziano, D. and Iacobellis, V.: Multiscaling pulse representation of temporal rainfall, Water Resour. Res., 38(8), 1138, doi:10.1029/2001WR000522, 2002.

Villani, P.: Extreme flood estimation using Power Extreme Value (PEV) distribution, Proceedings of the IASTED International Conference, Modeling and Simulation, edited by: Hamza, M. H., 470-476, Pittsburgh, Pa., 1993.

Viparelli, C.: Ricostruzione dell'idrogramma di piena L'Energia Elettrica, 6, 421-428, 1963 (in Italian). 